\title{
Study on Effective Maritime Training through the Anchoring Training
}

\author{
Y. Kunieda, K. Murai \& H. Kashima \\ Tokyo University of Marine Science and Technology, Tokyo, Japan \\ M. Sugawara \\ Japan Agency of Maritime Education and Training for Seafarers, Tokyo, Japan
}

\begin{abstract}
Anchoring exercises on a training ship have a significant effect on the acquisition of ship handling skills. Furthermore, such training is also effective for the development of critical thinking and problem solving. The authors investigated this topic to develop effective training methods for anchoring exercises. We created a rubric for anchor training, and the instructor evaluated trainees based on the rubric items. These rubrics were effective for judging trainee performance. The effect of dialogue in group work was shown by comments from instructors and the trainees. Group presentations were also evaluated via student comments. After conducting the anchoring training in native language in the spring, the same exercise was conducted in English in the fall. Only English instructions were offered during the training exercise in the first year (2016). In the second year (2017), students took a brief e-learning course in English about anchoring before attempting the second exercise in English. According to instructor evaluations, the second session in 2017 saw a much greater improvement in trainee performance than did the second session in 2016. English practice in the e-learning course allowed students to focus more on practising the techniques they had learned previously when performing the second training exercise in English.
\end{abstract}

\section{INTRODUCTION}

In maritime education and training, knowledge and skill transfer is achieved through classroom training and practical shipboard training. Lectures are generally given in the classroom. To achieve the desired effects, exercise assignments and experiments are combined. Trainees perform actual shipboard training independently, which is thought to be an active learning method. Compared with a lecture in which students passively listen to the speaker, practical shipboard training is thought to be more effective. Although actual shipboard training is effective, simple practice of the course content is not sufficient on its own. Students must also perform tasks that have been taught or decided upon within the practical session. Furthermore, effective training is important for active thinking and problem solving skills. It found that anchoring training on a training voyage has a significant effect on the acquisition of ship handling skills. (Kashima et al. (2001)) It found that anchoring training also helps students develop active thinking and problem solving skills. (Kunieda et al. (2018)) The following steps were involved in this study.

1 The effects of each student's training were collected from instructor responses to rubrics.

2 Subjective feedback from instructors and trainees was examined to find improvements to the training regime.

3 Improvement in overall ship handling skills was examined in terms of how anchor training improves information transfer across domains. 


\section{ANCHORING TRAINING}

Anchoring training is a suitable exercise for the improvement of ship handling. In this training, student teams practice without instructor assistance. First, the students heave up the anchor and sail a planned route. Then, after passing planned waypoints, the students drop anchor at the planned anchorage. The training exercise is performed in fourperson teams. Each team has one student in the role of captain (ROC), one as first officer ( $\mathrm{RO} 1 \mathrm{O})$, one as third officer (RO3O) and another as quartermaster (ROQ). Because the training is carried out in teams, the group work involves peer-to-peer learning. (Mochizuki (2013)) The steps of this exercise are listed below:

1 The ROC takes the lead and forms the navigation plan. This active student planning of the ship handling provides a leadership improvement opportunity for the ROC. Meanwhile, as the ROC explains the navigation plan to his or her teammates and instructors, and corrects the plan according to their feedback, opportunities for peer learning arise. (Mochizuki (2013)) After revising the ship handling plan, the ROC briefs the team members and instructors.

2 The ROC positions his or her crew when leaving the anchorage. He or she then calls on the $\mathrm{RO} 3 \mathrm{O}$ to start the general service pump for hauling up the anchor chains, directs the preparation of the main engine, and directs the hauling up of the anchor.

3 When the anchor is aweigh, the ROC directs the ship on a predetermined course using the main engine and rudder. Then, the ROC corrects the course appropriately so that the planned route is followed. The ship passes two scheduled waypoints and navigates the predetermined route.

4 The ROC slows the main engine, adjusting the course. He or she then stops the ship, applying the main engine to sternway, to drop anchor at the planned anchorage.

5 The ROC drops the anchor at the planned anchorage, lets out cables of predetermined length, and stops the main engine. He or she then dismisses the anchoring station.

6 The students carry out a self-evaluation using a rubric shortly after the end of the exercise. The rubric evaluation list that the instructors and students used contained the following nine items and the items were evaluated with a four-level indicator:

- Procedure for heaving-up anchor

- Course setting

- Look-out

- Give-way or stand-on ship handling

- Position fixing and anchoring position

- Anchoring procedure

- Gradual speed decrease

- Bridge resource management (BRM) / bridge team management (BTM)

- Overall training

7 After the exercise, each group discusses their performance. ROC presents to all the members the contents discussed in the team, and the other students listen to the presentation. In doing so, the students consider a range of issues and engage in active thinking. Strong points and points for improvement in training performance are discussed within each team. Then, the content discussed by each team is presented to the other teams. At the same time, the instructors' comments on the teams' performance based on the evaluation rubric are showed.

8 Students reflect on and suggest improvements to the rubric used in the self-evaluation.

\section{RESULTS}

67 third-year students in the undergraduate maritime system engineering course at Tokyo University of Marine Science and Technology performed the anchoring exercise in Japanese in May 2016. The same students repeated the exercise in October using only English. 67 more third-year students undertook the same sequence of exercises in May and October of 2017. The planned route and an example of an actual course taken by one of the ships are illustrated in Figure 1.

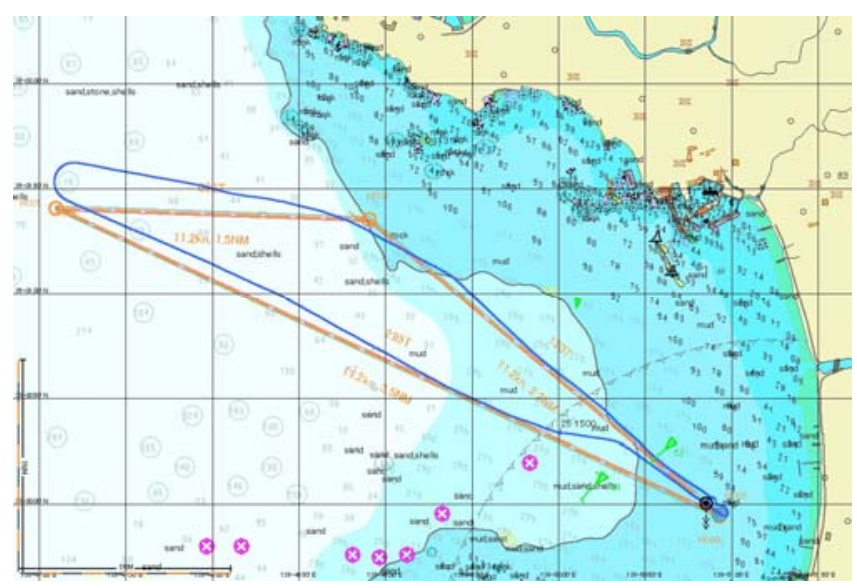

Figure 1. Planned route and training track.

\subsection{Instructors' evaluation results and e-learning of Maritime English}

In the anchoring exercise, two instructors who are experienced in captaining a large training ship evaluated the trainees using a rubric. In the rubric, each item is rated from 1 to 4,4 indicating excellent performance. The average evaluation scores of two instructors per each item for each session are shown in Table 1. Anchoring training in May 2016 is shown as '2016 (1)', anchoring training in October 2016 is shown as '2016 (2)', anchoring training in May 2017 is shown as '2017 (1)', and anchoring training in October 2017 is shown as '2017 (2)'. The average rubric scores from all four training sessions are shown in Figure 2. 
Table 1. Instructors' average evaluation scores for each session

\begin{tabular}{|c|c|c|c|c|c|}
\hline \multirow{2}{*}{\multicolumn{2}{|c|}{ No. Evaluation Item }} & \multicolumn{4}{|c|}{ Average Evaluation Score } \\
\hline & & $\begin{array}{l}2016 \\
(1)\end{array}$ & $\begin{array}{l}2016 \\
(2)\end{array}$ & $\begin{array}{l}2017 \\
(1)\end{array}$ & $\begin{array}{l}2017 \\
(2)\end{array}$ \\
\hline \multicolumn{3}{|c|}{$\begin{array}{l}1 \text { Procedure for heaving-up } 2.91 \\
\text { anchor }\end{array}$} & 2.94 & 3.13 & 3.71 \\
\hline 2 & Look-out & 1.84 & 2.06 & 2.19 & 2.64 \\
\hline 3 & Course setting & 1.75 & 2.50 & 2.00 & 2.36 \\
\hline & $\begin{array}{l}\text { Give-way or stand-on } \\
\text { ship handling }\end{array}$ & 1.84 & 2.31 & 2.28 & 2.86 \\
\hline 5 & $\begin{array}{l}\text { Position fixing and } \\
\text { anchoring position }\end{array}$ & 2.19 & 2.81 & 2.25 & 2.36 \\
\hline 6 & Anchoring procedure & 2.63 & 2.75 & 3.03 & 3.14 \\
\hline 7 & Gradual speed decrease & 2.44 & 2.38 & 2.72 & 3.43 \\
\hline 8 & BRM/BTM & 1.97 & 2.38 & 2.44 & 3.43 \\
\hline 9 & The whole of the training & 1.84 & 2.44 & 2.19 & 3.43 \\
\hline & Average & 2.16 & 2.51 & 2.47 & 3.04 \\
\hline
\end{tabular}

points

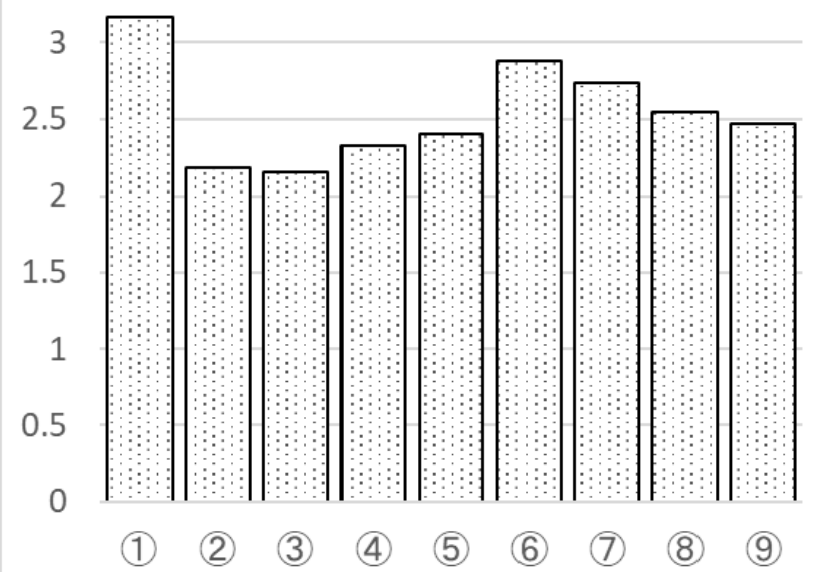
(1) Procedure for heaving-up anchor
(2) Lookout
(3) Course setting
(4) Give-way or stand-on ship handling
(5) Position fixing and anchoring position
(6) Anchoring procedure
(7) Gradual speed decrease
(8) BRM/BTM
(9) The whole of the training

Figure 2. Average value of each evaluation item

According to Table 1 and Figure 2, the highestevaluated items were 'Procedure for heaving-up anchor', 'Anchoring procedure' and 'Gradual speed decrease.' On the other hand, the items 'course setting', 'look-out' and 'give-way or stand-on ship handling' were relatively low.

The average values of all evaluation items for each year and each session are shown in Fig. 3. Fig. 3 shows that the second session was rated better than the first in both 2016 and 2017. A greater increase in scores occurred over the two sessions in 2017; the session scores were different by $16.3 \%$ in 2016 , and differed by $23.1 \%$ in 2017 . Based on the result of $F$ test of two specimens, $t$ test assumed to be equal distribution was performed. As a result, it was $p>0.05$ in 2016. On the other hand, it is $p<0.05$ and the significant difference was shown in 2017.

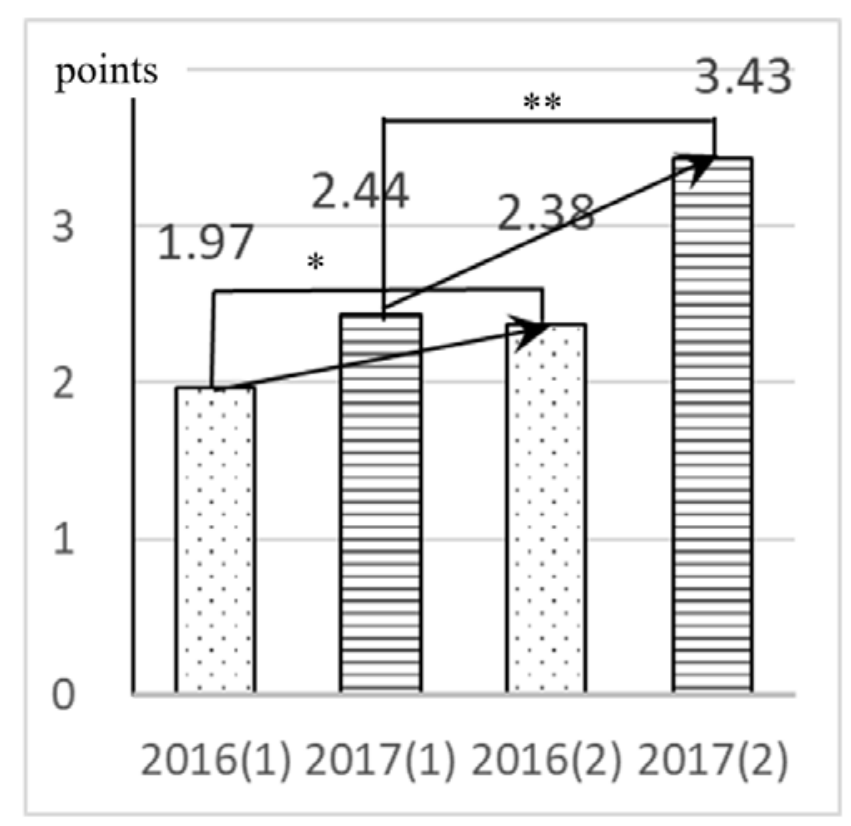

Figure 3. The average value of all evaluation items in 2016 and 2017

The evaluation score of BRM/BTM in 2016 and 2017 are shown in Figure 4.

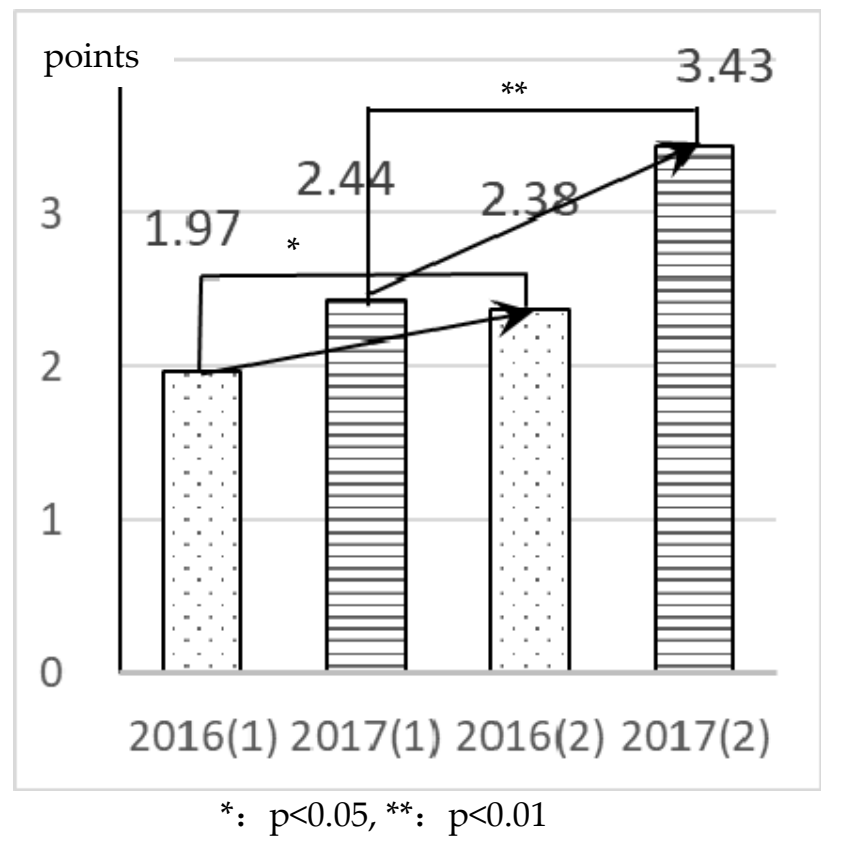

Figure 4. Evaluation scores of BRM/BTM in 2016 and 2017

Figure 4 shows that evaluation scores improved by $40.7 \%$ in 2017 , while the increase in performance in 2016 was $20.6 \%$. And concerning the result of $t$ test, it was $p<0.05$ in 2016, and was $p<0.01$ in 2017. The significant difference was shown for both years and especially 2017 were remarkable.

The first anchoring exercise in May was carried out in Japanese, and the second exercise in October was conducted in English, in both years. We expected that trainees would find the English-language exercise more difficult. The trainees filled out a questionnaire about the difficulty of performing the exercise in English to assess this expectation. The results of the questionnaire are shown in Fig. 5. The upper graph shows results from 2016 and the lower 
graph shows results from 2017. The students in 2017. Those who answered felt it as the burden very much from the figure tended to find English-language to be less of a burden.

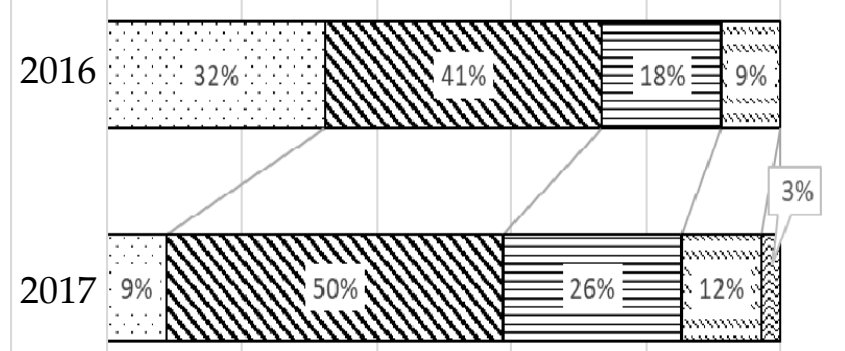

$\begin{array}{llllll}0 \% & 20 \% & 40 \% & 60 \% & 80 \% & 100 \%\end{array}$

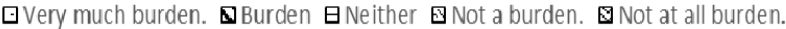

Figure 5. Feedback about the burden of training in English

Only English worksheets about the anchoring training were distributed to the trainees in 2016. On the other hand, trainees completed an e-learning course about the anchoring training beforehand in 2017 , and trainees needed to score $90 \%$ or more of on an examination before undertaking the shipboard exercise. The trainees in 2017 were therefore more prepared to undertake the exercise in English. As a result, an instructor commented in 2017 that the trainees did not struggle with English as much as they did in 2016.

\subsection{Instructor comments}

The instructors' comments written in the comments field of the evaluation list include technical and nontechnical content; some are listed below:

Technical comments:

1 Understanding of the procedure of hauling the anchor up was insufficient and there was wasted time.

2 The use of bow and stern marks was insufficient, and the course setting was not appropriately completed.

3 In one case, the passing distance from fishing boat was too small.

4 Because there was too much focus on a single detail, the whole could not be grasped.

5 Because the trainee was not able to understand terms such as 'distance to new course' or 'wheel over point', steering was sometimes late.

6 Because the trainee's grasp of the ship's position was insufficient, the slowdown was late.

The technical fields included:

1 Content about the ship's manoeuvring

2 Content about the ship-handling for giving way to other vessels

3 Content about the ship's positioning

The following comments were of a non-technical nature.
1 Trainees' understanding of the planning for ship handling was sound, because the planning process was discussed and recreated many times.

2 Because the prior preparation was sufficient, the procedures for hauling up the anchor and for anchoring were executed well.

3 Because role playing before the exercise and visualisation training were inadequate, trainees' reactions to unpredictable situations were insufficient.

4 Because the reports to the ROC were timeconsuming, the trainees in the ROC did not sufficiently grasp them.

5 Although the trainee in the ROC depended too much on the trainee navigation officer, he or she remained aware of team management.

6 The trainee became too stressed to understand the appropriate action to take.

Non-technical fields in the feedback report included:

1 The effects of group work

2 The effects of prior training

3 Management of resources and teamwork

\subsection{Trainee comments}

Trainee comments were organised into positive feedback about the exercise and suggestions for improvement. The most frequent comments are listed below:

1 Other groups' feedback could be heard, so we were able to use these points to improve our own ship-handling.

2 Because we formed the navigation plan independently, and we had the opportunity to perform it, we learned about all aspects of shiphandling.

3 Each of us trained responsibly within a small group.

4 Discussion about navigation planning within our group was effective.

5 Understanding was deepened by the independent thinking in the exercise.

6 We cooperated well with our team-mates because of the clearly defined roles.

Trainees gave many comments that were positive about the exercise.

The following comments were the main improvements suggested by trainees:

1 The influence of wind and current could have been taken into account better.

2 I looked out in all directions, without focussing on any one thing.

3 I learned to perform the look-out and report according to the intentions of the trainee in the ROC.

4 I should achieve ship positioning and make positioning reports more quickly.

5 Targets could be better understood in advance using a chart.

6 Persons in other roles gave information to the trainee in the ROC effectively.

7 The captain trainee needs to keep all aspects of the exercise in mind. 
Non-technical improvements, such as advance preparation and sharper mental attitude, were also suggested.

\section{DISCUSSION}

\subsection{Instructor evaluations}

According to the instructors' evaluation, the procedures for hauling up and dropping the anchor were followed well. These procedures were effectively memorised by the trainees. Most trainee teams slowed the ship down effectively, in a gradual manner. On the other hand, many trainee teams struggled to set a course appropriately and modify it according to the situation. Moreover, trainees tended to perform poorly in terms of looking out for fishing boats, and incoming and outgoing ships.

Trainee performance increased more between the two sessions in 2017. We believe that this trend gives evidence of the effectiveness of the English e-learning course that trainees took before the exercise in 2017. Fewer students found English-language communication to be a burden in 2017. The improved comfort with communication skills encouraged by the e-learning course allowed trainees to focus more on ship-handling tasks in the second session of 2017.

\subsection{Comments}

The comments from instructors and trainees were about four stages of the exercise: planning, execution, evaluation and improvement.

These stages suggest that the anchoring exercise can be framed as a Plan-Do-Check-Act (PDCA) cycle. There is planning of the ship handling as a plan. As execution, the anchoring training is carried out. As evaluation, mutual evaluation and self-evaluation are performed during and after the exercise. The rubric feedback is incorporated in the second training exercise, as an opportunity for improvement. The instructor reviews are also incorporated into the improvement step. The PDCA cycle tends to be effective. This cycle guides us to offer the following improvements to future iterations of the anchoring training exercise:

1 Group work in the planning stage: Implementation of dialogue, exchange of opinions and discussion within the group is very effective. Instructor facilitation of the group work planning is essential.

2 Instructors' cheque in the planning stage: Trainees improve by following the instructors' advice. Thinking independently about the instructor's advice and improving has an effect in promotion of an understanding and in acquisition of knowledge. After listening to an explanation from the trainee, the instructor gives feedback so that the trainee can think independently in the rest of the planning phase.

3 Briefing in the planning stage: Information sharing in a group, clarification of role assignments and duplicate cheques can be incorporated in a briefing during the navigation planning phase. Trainees could discuss the briefing content quickly, and ask instructors for advice about cooperation among the team.

4 Briefing in the planning stage: When the ROC trainee explains the ship handling plan to instructors and trainees, the ROCs' own understanding of the plan deepens.

5 Simulation in the planning stage: The implementation of a simulation that considers the effects of various factors on the navigation plan could be helpful.

6 Creation of the evaluation list in the planning stage: Trainees could generate their own rubrics before completing the exercise. Choosing evaluation items helps trainees to consider the important parts of the exercise.

7 Goal setting in the execution stage: The distance of the targets from the planned route is set up at the time of a route sailing, along with the distance between the target and the planned anchorage site. The Distance of Closest Pointed Approach to the target is determined if the ship needs to give-way to another vessel. These benchmarks increase trainee motivation.

8 Ship handling intention manifested in the execution stage: As part of BRM/BTM, the trainee of the ROC can promote his or her own understanding by communicating intentions clearly to the rest of the team.

9 Directions in the execution stage: The ROC trainee directs required work to the team members. Thereby, while ROC relays the ship handling intentions, independent thinking is promoted by situational work commands.

10 Assistance in the execution stage: $\mathrm{RO} 1 \mathrm{O}$ and RO3O carry out the work and report on their progress to the ROC. The navigation officer should also think from the perspective of the captain to promote understanding.

11 Self-evaluation in the evaluation stage: With selfevaluation, the ROC reviews his or her shiphandling skills and considers individual improvements.

12 Peer review in the evaluation stage: By evaluating team members, the trainee notices aspects of shiphandling that require special attention, and thinks of improvements, which encourages long-term retention.

13 Improvement of the evaluation list in the improvement stage: The trainee's understanding ship-handling could be deepened by improving the evaluation items and criteria of the evaluation list of rubric form. The improvement of evaluation items can clarify aspects of ship-handling that require special attention.

14 Group work in the improvement stage: Discussing the good points and points for improvement after training leads to the improvement of a trainee's ship handling skills. As trainees reflect independently and in dialogue, this step can dramatically improve the training's effectiveness.

15 Presentation in the improvement stage: Presentation of the results achieved by the team helps with mastery. Moreover, trainees can learn from other teams who experienced different circumstances.

16 Instructors' debriefing in the improvement stage: The trainees obtain new awareness of knowledge and skills by listening to the explanation from the 
instructor. This awareness is not obtained from the trainees' presentations alone.

17 Assignment in the improvement stage: Trainees should complete independent work after the exercise to encourage long-term retention. Trainees could prepare a revised ship-handling plan independently as an at-home assignment.

By participating in this training, the trainees learned to think for themselves, use judgement and perform skilled practical tasks. By thinking for themselves, we believe that trainees become capable of making a suitable correspondence to other situations.

Takahashi (2008) showed that group work increases student motivation. In particular, group work in the planning stage is effective, based on the comments from the instructors and trainees. The ship handling briefing, which is usually carried out while entering the port, is also effective. Moreover, the effect of this briefing is greater because he instructor adds suitable facilitation. Instructor facilitation is indispensable, especially for the trainees who have minimal ship handling experience. Regarding facilitation, some strategies promote intellectually creative activities, as shown by Oishi (2008). When an instructor gives suitable advice, trainees think by themselves and become capable of performing the better skills of ship handling. As for more effective and more suitable facilitation, further observation is required.

In the execution stage, thinking is needed during the act of execution, and correspondence with various situations is needed. According to the situation at a given time, trainees must consider the relative positions of fishing boats, fishing gear, or other vessels, and they must adjust the navigation plan independently. Moreover, according to the situation at hand, trainees must respond to wind and currents. This independent thinking increases the effectiveness of the exercise.

In the evaluation stage, reflection occurs during self-evaluation and peer review. Through this reflection, the trainees' understanding of ship handling progresses and an improvement in their ship handling skills is achieved. In the self-evaluation, trainees consider their ship handling deeply and are conscious of the points that should be improved. In peer review, other groups' good points are adopted by the trainees themselves, and the points for improvement are considered as reference for future ship handling.

In the improvement stage, we believe that summarising the improvements on the evaluation list and the improvement in one's ship handling ability improves trainees' skills. Moreover, notifications about ship handling are obtained from group work during the team debriefing. Similarly, by giving group presentations, trainees identify points to fix about their team work.

\section{SUMMARY}

In May, anchoring training was conducted in Japanese, which is the students' native language. The same anchoring training was conducted in English five months after. The same sequence of exercises was repeated the next year. Although the October sessions were more difficult due to the use of English, performance improved in both years because the trainees had completed the exercise once before. Performance improved much more between the two sessions in the second year. This difference is explained by the online pre-training in English that was required before the second session in the second year. Trainees struggled more with English-language terms in the first year because they had not completed this e-learning course. Trainees were therefore more prepared to communicate about ship-handling in English in 2017. The anchoring exercise involves every aspect of handling the ship. Each element of those skills, including communication between crewmembers, is important to overall performance. This study shows that repetition of the training exercise is effective for encouraging performance improvement, and that undergoing the training exercise in a second language can effectively encourage critical thinking and skill transfer across the domains involved in handling a ship.

\section{REFERENCES}

Kashima, Hideyuki, et al., 2001. About the Training Effect of Ship Handling Training. Journal of the National Institute for Sea Training, 1, 17-38.

Kunieda, Yoshiaki, et.al., 2018. Study on Education of Seamanship in the Anchoring Training, the 16th World Congress of the International Association of Institutes of Navigation Proceedings, 77-82

Mochizuki, Michiko, 2013. On Peer Learning and Learning Process in JSL Learners, Kansai University, Bulletin of Faculty of Foreign Language Studies, 8, 87-97.

Oishi, Kanako, 2008. Technique of Facilitation-Talks to Active Engineering Design Education. Journal of Japanese Society for Engineering Education, 56(6), 176-180.

Takahashi, Toshio, 2008. Toward More Active Classroom Interaction-A Consideration of Implementing Learnercentred Group Work in Class, Kansai University forum for foreign language education, 7, 23-34. 